\title{
REDUCED CHEMICAL REACTION MECHANISMS : EXPERIMENTAL AND \\ HCCI MODELLING INVESTIGATIONS OF AUTOIGNITION PROCESSES \\ OF ISO-OCTANE IN INTERNAL COMBUSTION ENGINES
}

\author{
H. Machrafi ${ }^{1}, \underline{\text { K. Lombaert }}{ }^{2 *}$, S. Cavadias ${ }^{1}$, P. Guibert ${ }^{2}$, J. Amouroux ${ }^{1}$ \\ *Corresponding author : lombaert@ccr.jussieu.fr \\ 1: Laboratoire de Génie des Procédés Plasma et de Traitement de Surface, ENSCP, 11, Rue Pierre et \\ Marie Curie, 75005 Paris, France. \\ Tél: +33144276719 - Fax : +33143227324 \\ 2 : Laboratoire de Mécanique Physique, CNRS UMR 7068, Université Pierre et Marie Curie, \\ 2, Place de la Gare de Ceinture, 78210 Saint Cyr l’Ecole, France. \\ Tél: +33130854890 - Fax : +33130854899
}

\begin{abstract}
A semi-reduced (70 species, 210 reactions) and a skeletal (27 species, 29 reactions) chemical reaction mechanism for iso-octane are constructed from a semi-detailed isooctane mechanism (84 species, 412 reactions) of the Chalmers University of Technology in Sweden. The construction of the reduced mechanisms is performed by using reduction methods such as the quasi-steady-state assumption and the partial equilibrium assumption. The obtained reduced iso-octane mechanisms show, at the mentioned conditions, a perfect coherence with another more detailed iso-octane mechanism of ENSIC-CNRS (2411 reactions and 473 species) and the semi-detailed iso-octane mechanism of Chalmers. The validity of this mechanism with regard to the ignition delay is determined for several engine parameters adhering to HCCI conditions : inlet temperature (303-363 K), equivalence ratio (0.2-0.7) and compression ratio (1016). The ignition delay is found to be decreased by an increase in the inlet temperature,
\end{abstract}


a decrease in the equivalence ratio and an increase in the compression ratio. In order to validate the effects of the inlet temperature, compression ratio on the auto-ignition delay, experiments are performed on a CFR engine. A good agreement is obtained between experimental results and calculations.

\section{Key-words : autoignition, iso-octane, engine, HCCI}

\section{Introduction}

Strategy of the automobile industry implies developing new engines functioning with a low equivalence ratio, lower fuel consumption and consequently reducing $\mathrm{CO}_{2}, \mathrm{NO}_{\mathrm{x}}$ and particulate emissions. Respecting the Euro IV emission norms in 2005 (Table 1), post-treatment (the catalytic oxidation, the $\mathrm{NO}_{\mathrm{x}}$ traps and the particulate traps) can be used. A new combustion process, named HCCI (Homogeneous Charged Compression Ignition), appears to be a good solution to respect the future Euro norms (Table 1). Using a premixed air-fuel mixture and a lean burn combustion process at lower temperatures, the HCCI combustion allows to obtain a higher thermal efficiency, low $\mathrm{NO}_{\mathrm{x}}$ emissions and low particulate-matter emissions [1] (Figure 1). Contrary to diesel combustion, where turbulence during flame diffusion is of great importance or gasoline combustion with a flame front propagation, the auto-ignition phenomenon in an HCCI engine is mainly controlled by chemical kinetics.

Over recent years, a number of papers describe the auto-ignition for many compounds at lower temperatures $(300-345 \mathrm{~K})$ and higher pressures $(0.53-14$ bar) $[2,3,4,5]$. Currently, most of HCCI investigations use iso-octane as a fuel [6], due to the great interest to improve the efficiency of engines and to reduce their pollution. Iso-octane is a primary reference fuel for octane rating in spark ignition engines and has a cetane number of 15 when used in compression ignition engines [6]. 
Hydrocarbon ignition can occur in two significantly different stages $[2,3,4]$, which depends on the initial temperature (for example during $\mathrm{n}$-heptane and $\mathrm{n}$-decane combustion at low temperatures $[2,7])$.

At low initial temperature regimes $(\mathrm{T}<700 \mathrm{~K})$, during the first stage, fuel forms hydrocarbon radicals thanks to hydrogen abstraction. Then, these compounds could be isomerized or could react with $\mathrm{O}_{2}$ to form peroxides. During this first stage, temperature and pressure increase slightly. Figure 2 shows the general form of a cool flame [8].

Then, the temperature continues to increase until reaching an intermediate temperature zone $(700-1000 \mathrm{~K})$ where small radicals such as $\mathrm{HO}_{2}$ are formed. The $\mathrm{HO}_{2}$ radicals react further with the fuel to form $\mathrm{H}_{2} \mathrm{O}_{2}$. Then $\mathrm{OH}$, formed by the decomposition of $\mathrm{H}_{2} \mathrm{O}_{2}$, leads to the second stage combustion [9]. In this step, the $\mathrm{OH}$ radicals (far more important than other radicals formed from chain branching) consume the fuel (the cool flame ends), resulting into a sudden temperature rise (up to $3000 \mathrm{~K}$ or more, in case of a rich mixture) and pressure increase (the second stage begins).

The first stage could be detected by studying the blue light, a characteristic color for the emission of HCHO* (Figure 2), formed during this step $[10,11,12]$. Depending on the fuel chemistry, in some cases at a given pressure and for some low initial temperature (lower than $750 \mathrm{~K}$ ), the oxidation process slows down whereas the temperature increases. This is the main characteristic of the Negative Temperature Coefficient (NTC) regime (Figure 3). In this zone, the formation of $\mathrm{HO}_{2}$ radical becomes more important than the isomerisation reactions and the peroxide formations. $\mathrm{HO}_{2}$ radicals are more stable than $\mathrm{OH}$. Moreover, the propagation reaction with $\mathrm{HO}_{2}$ is less exothermic than that with the $\mathrm{OH}$ radical [13]. Then, when the temperature is high enough for the $\mathrm{OH}$ reaction to become more important, the reaction rate increases with the temperature. 
After this region, at higher inlet temperature $(\mathrm{T}>900 \mathrm{~K})$, the ignition takes place in a single stage.

In this paper the cool flame delay is taken as the ignition delay, corresponding to the maximum temperature sensitivity for Chemkin ${ }^{\circledR}$.

\subsection{HCCI chemistry}

As is mentioned previously, the HCCI chemistry is mainly controlled by the chemical kinetics at lower temperatures that precede the auto-ignition. Indeed, the HCCI combustion process could be applied widely in engine applications if precise prediction of ignition timing for variable experimental conditions is involved. So it is important to understand the mechanisms that take place during the ignition delay. The first reactions that govern the combustion initiation, are listed in Table 2 (reactions 1 to 5).

At low temperatures $(\mathrm{T}<900 \mathrm{~K})$ reaction 3 and 4 represent the main initiation reactions of the consumption of iso-octane. After the formation of octyl radicals $\left(\mathrm{C} 8 \mathrm{H} 17^{*}\right)$, these react further forming several peroxide radicals $(\mathrm{C} 8 \mathrm{H} 17 \mathrm{OO} *)$ and eventually the hydroxyl radical $\mathrm{OH}^{*}$ [14], via a sequence of reactions (reaction 6 to 11). These peroxide radicals and the hydroxyl radical play an important role in the oxidation process $[7,14]$, since the reactions concerning the formation of the peroxide radicals and hydroxyl radical release a great amount of energy ( $\Delta \mathrm{H}$ varies from -110 to -130 $\mathrm{kJ} /$ mole). Finally the hydroxyl radical consumes rapidly iso-octane (reaction 2), resulting into a rapid increase in the temperature and eventually the auto-ignition [2]. At higher temperatures $(\mathrm{T}>900 \mathrm{~K})$, however, reaction 1 promotes the combustion process. A decomposition into smaller radicals and olefins govern the main combustion process which is now a one-stage combustion $[14,8]$. According to the chosen kinetic scheme, the formed pentyl radical decomposes further into propene and an ethyl radical 
H. Machrafi et al.

releasing altogether a great amount of heat $(\Delta \mathrm{H}$ takes the value of about $-130 \mathrm{~kJ} / \mathrm{mole})$ (reaction 12).

\subsection{Effects of physical parameters on the ignition delay}

When implying HCCI combustion, the major problem that appears, is the control of the ignition delay. Several physical parameters affect the quality of the HCCI combustion and the ignition delay: mixture homogeneity, inlet temperature of air and fuel, fuel composition, kinetics of the fuel oxidation at lower temperatures and thermal effects (heat exchange, thermal loss to the wall, EGR ratio mixture quality) $[7,15,16,2,14]$. A better understanding of the influence of these parameters on the ignition time is required, to have a more thorough knowledge of the HCCI combustion process and consequently of the application on an engine.

The main parameters, studied the most in the literature $[7,15,16,2,14]$, are the inlet temperature, the equivalence ratio and the compression ratio. In order to determine the influence on ignition delay, Ogink and Golovitchev [15] have performed calculations on varying the inlet temperature $(600 \mathrm{~K}$ to $1400 \mathrm{~K})$ and pressure $(10 \mathrm{~atm}$ to $40 \mathrm{~atm})$. For iso-octane they have determined that a higher initial pressure and inlet temperature result into a lower ignition delay. Soyhan and Mauss [16] have determined the influence of the inlet temperature on the ignition delay, but only at inlet temperatures higher than $700 \mathrm{~K}$. With respect to the influence of the inlet temperature on the ignition delay they have come to the same conclusion as Ogink and Golovitchev [15]. N-heptane, however, shows a different trend at inlet temperatures around the cool flame. As a consequence of the NTC, as explained before, an increase in the inlet temperature, causes an increase in the ignition delay.

To predict satisfactorily the auto-ignition delay in an engine, the rate of heat release or emissions' formation, it is necessary to use a realistic modelling of the chemical process 
with a lower inlet temperature. Since a large number of intermediate species participate in a great number of elementary reactions during fuel oxidation, it is very difficult to add this entire mechanism in a Computational Fluid Dynamics (CFD) code. Therefore, it is necessary to reduce a detailed mechanism and to determine the validity of the reduced mechanism, prior to its utilization for predicting the aerodynamic effects in an engine cylinder using CFD codes such as Fluent or StarCD.

This paper's main interest involves producing a reduced mechanism that predicts accurately the ignition delay and pressure curves for several equivalence ratios (0.20.7), compression ratios (10-16) and air inlet temperatures (303-363 K). Specific engine parameters (cylinder capacity $611 \mathrm{~cm}^{3}$, initial pressure $1 \mathrm{~atm}$ and engine speed $600 \mathrm{rpm}$ ) are used. In addition to previous experiments $[15,16]$, very low temperatures are studied, since the goal of HCCI engines is to operate at lower temperatures [17].

In this paper, a description of the method used to reduce the iso-octane detailed chemical mechanism is presented and several effects of engine parameters (equivalence ratio, compression ratio and inlet temperature of the mixture) are investigated. A validation of these influences on a CFR engine is also presented.

\section{Reduction of the iso-octane mechanism}

This section describes the reduction methodology of the iso-octane mechanism [18]. This mechanism is developed and provided by the Chalmers University of Technology in Sweden, containing 412 reactions and 84 species. This mechanism has previously been validated successfully at the Chalmers University of Technology in a reactor between 10 and 40 bar [18]. Reduction is performed using Aurora, provided in the Chemkin collection 3.7 package. Even if the simulation of auto-ignition on an engine is performed at very low temperatures, the validity of this reduced mechanism has to be determined by simulating the ignition delay at inlet temperatures between 300 and 1300 
$\mathrm{K}$. The capability of this reduced mechanism and the accurate prediction of the ignition delay can be hereby determined with respect to the validated Chalmers mechanism. Furthermore, to check the validity of the Chalmers mechanism as well as the reduced mechanism, these are also compared with the more detailed mechanism (2411 reactions and 473 species), provided by the ENSIC-CNRS laboratory in Nancy (France) [19]. This last mechanism has been already validated successfully in a jet-stirred reactor at $923 \mathrm{~K}$ under 1 bar [20].

The reduction of the Chalmers mechanism is obtained by eliminating reactions in a manner to keep the same predictability as the initial Chalmers mechanism (the obtained model must be very accurate and only $5 \%$ of fluctuations on the ignition delay is allowed. The reduction is performed using a method developed by Peters in 1987 $[8,21,22]$, which comprises several steps [16,22]. Firstly, using the analysis of the conversion rate of the reactant species, the redundant species were removed $[23,8]$ from the Chalmers mechanism obtaining a semi-reduced mechanism with 210 reactions and 70 species. Secondly, by introducing the quasi-steady-state assumption [21] and, thirdly, the partial equilibrium assumption [8]. The semi-reduced mechanism was further reduced, obtaining the skeletal mechanism of 29 reactions and 27 species. The quasi-steady-state assumption is a classical hypothesis in the domain of combustion chemistry. It consists of assuming an equilibrium between the production and consumption of certain intermediary species that are very reactive [8,23,22] (on calculating the rate constants), with a short lifetime [24] and in small quantities (due to the high reactivity). For example, a certain species' concentration is very low [22] and constant due to the fact that it is produced very slowly and consumed very rapidly. Here this species can be eliminated and the two concerning reactions can be merged into one, hereby eliminating one [8]. The partial equilibrium assumption is also a classical hypothesis whereby an equilibrium is assumed between the reaction rates in the direct 
and the inverse direction of certain reversible reactions that are very rapid $[8,22]$. This approach (or even just the quasi-steady-state assumption alone) proved to be successful for the construction of reduced chemical kinetic schemes [8, 23, 24, 21, 22] for the combustion of several hydrocarbons $[16,20]$. The same method was used by Soyhan and Mauss [16] when they reduced their mechanism (for mixtures of iso-octane and nheptane) from 510 reactions and 74 species until 16 global reactions and 19 species with acceptable accuracy.

After the reduction process and the optimization of the Arrhenius coefficients, a reduced mechanism, described in Table 3, containing 29 reactions and 27 species, is obtained with perfect accuracy on ignition delay compared to the Chalmers mechanism and the Nancy mechanism.

\section{Results and discussion}

\subsection{Numerical validation of the reduced mechanisms with respect to the Chalmers} and Nancy mechanism

Before continuing with the reduced mechanism, it is necessary to validate this mechanism numerically. The validity of the skeletal and the intermediary mechanism is tested for several engine parameters on calculating the ignition delays using an HCCI internal-combustion engine-cylinder program in Chemkin, simulating a compression and expansion stroke in one cycle (the intake and exhaust stroke are not considered). Hereby the compression ratio, equivalence ratio and inlet temperature were varied, keeping the inlet pressure at 1 bar and the combustion adiabatic (Table 4). The obtained results are compared to the detailed Chalmers and Nancy mechanisms.

Figure 4 shows that the complete iso-octane mechanism, obtained from Nancy, is in a good agreement (error less than 5\%) with the Chalmers mechanism (and also the reduced mechanism of 29 reactions), below a temperature of $600 \mathrm{~K}$. From $600 \mathrm{~K}$ up to 
$1100 \mathrm{~K}$ the Nancy iso-octane mechanism is comparable with the Chalmers mechanism and the ignition time does not differ more than $10 \%$ from the Chalmers mechanism. Even though the two mechanisms differ considerably for inlet temperatures higher than $1100 \mathrm{~K}$, this is not regarded to be in our interest. Since the interests of this paper are related to conditions of an engine (inlet temperature engine: $300 \mathrm{~K}<\mathrm{T}<360 \mathrm{~K}$ ), the reduced mechanism of 29 reactions and 27 species can be perfectly used for further calculations of the influence of equivalence ratio, inlet temperature and compression ratio on the ignition delay and will be introduced in a CFD code in the future.

Figure 4 illustrates that at lower temperatures $(\mathrm{T}<600 \mathrm{~K})$ the semi-detailed and skeletal mechanisms predict the ignition time very well with regard to the Chalmers and Nancy mechanisms. At intermediate inlet temperatures $(600 \mathrm{~K}<\mathrm{T}<750 \mathrm{~K})$ the two reduced mechanisms predict the ignition time with acceptable accuracy $(<5 \%$ error $)$. At higher inlet temperatures $(\mathrm{T}>750 \mathrm{~K})$ the prediction of the ignition time by the semi-reduced mechanism with 210 reactions corresponds nicely with the Chalmers mechanism with regard to the trend. However, with regard to the Chalmers results of the ignition time, the semi-reduced mechanism with 210 reactions shows a relative error between approximately $5 \%$ and $40 \%$, depending on the inlet temperature. The reduced mechanism, with 29 reactions, deviates significantly from the Chalmers mechanism at temperatures higher than $750 \mathrm{~K}\left(1000 / \mathrm{T}<1,3 \mathrm{~K}^{-1}\right)$. This is due to the fact that the reduction is done with the objective to simulate the ignition delay at lower inlet temperatures $(300<\mathrm{T}<750 \mathrm{~K})$.

Having determined the numerical validity of the reduced mechanism successfully in a wide range $(300 \mathrm{~K}<\mathrm{T}<1100 \mathrm{~K})$, some important parameters that influence the ignition delay will be determined at an inlet temperature regime that befits the range of an engine $(300 \mathrm{~K}<\mathrm{T}<400 \mathrm{~K})$. Simulations are made, determining the influence on the ignition delay of mechanical parameters - the inlet temperature $(303 \mathrm{~K}-363 \mathrm{~K})$ and the 
compression ratio $(10-16)$ - and a chemical parameter - the equivalence ratio $(0.2-$ 0.7). The ignition delays are calculated using Chemkin software (time when the maximum of sensitivity in temperature is obtained) and are expressed in Crank Angle Degrees, where 0 CAD signifies the combustion Top Dead Center (TDC). Therefore, the value obtained is usually negative. Note, that in this case the ignition delay is defined with respect to the TDC (an ignition delay of -5 CAD means that fuel autoignites 5 CAD before TDC).

\subsection{Effects of the inlet temperature on auto-ignition delay}

Figure 5 shows that the overall reaction rate is higher at elevated temperatures, causing the ignition time to decrease. The same trend was observed by Ogink and Golovitchev [15] or Soyhan and Mauss [16] during the study of iso-octane combustion. Figure 5 shows also for an equivalence ratio of 0.2 and 0.6 the comparison of the mechanism of 29 reactions with the Chalmers mechanism. In this studied conditions, it is clear that both mechanisms correspond perfectly for different equivalence ratios at the lower inlet temperature regimes.

\subsection{Effects of the equivalence ratio on auto-ignition delay}

Figure 5 shows that the ignition time increases (slower combustion) with increasing equivalence ratio. According to the literature [7], two different temperature regimes are present in the iso-octane combustion and two different initial mechanisms prevail the outcome of the combustion initiation. Ogink [15] explains this phenomenon with respect to $n$-heptane and states that the mechanism of iso-octane is very similar. At inlet temperatures lower than $850 \mathrm{~K}$, the first sequence that controls the combustion initiation, contains the reactions beginning with the oxidation of iso-octane, which produce peroxide radicals [10] and subsequently $\mathrm{OH}$ radicals after a series of reactions 
[14]. Since this paper focuses on the low temperature regime $(300 \mathrm{~K}<\mathrm{T}<400 \mathrm{~K}$ ), this increase of ignition time with the equivalence ratio could be explained further regarding the mechanism at the lower temperature regime. In the lower inlet temperatures regime, a higher equivalence ratio, which provides less $\mathrm{O}_{2}$ for the iso-octane to react with, causes a lower overall reaction rate and thus a higher ignition delay. This is also observed by MacNamara and Simmie [25] who state that the ignition delay of the combustion of pyridine and pyrrole shows a negative oxygen concentration dependence. The combustion of methane [kim] shows the same observation as did the oxidation of propane [Aieghamailf]. So the overall reation ate is primarily depentent on the $\theta_{2}$

To illustrate the previous observations, as is shown in Figure 6, iso-octane is considerably consumed only just after the ignition time (respectively - 17.4 CAD and 12.0 CAD). In this figure, the concentrations are normalized with the total number of molecules introduced in the mixture whereas the heat exchange represents the emitted enthalpy during gaseous reactions. This shows the independency of the ignition time on iso-octane quantity. Figure 6 also shows that before the ignition time (after a sequence of rapid reactions, initiated from the reaction between iso-octane and oxygen) the peroxide radicals $\mathrm{C}_{8} \mathrm{H}_{17} \mathrm{OO}, \mathrm{C}_{8} \mathrm{H}_{16} \mathrm{OOH}$ and $\mathrm{C}_{8} \mathrm{H}_{16} \mathrm{OOHOO}$ are formed. This means that the ignition delay is dependent on $\mathrm{O}_{2}$, since oxygen is responsible for the formation of the peroxides. The formation of the peroxide radicals are responsible for the energy release (and the pressure rise) and the $\mathrm{OH}$ production that consume the iso-octane. This means that at lower temperatures the overall reaction rate is governed by the initiation of the reaction between iso-octane and oxygen and also by the formation of peroxide radicals [7]. $\mathrm{CH}_{2} \mathrm{O}$ is being formed just before the ignition time, as a consequence of the cool flame as is shown by a slope modification on the pressure curve in Figure 6 . This is also observed by Lewis and Von Elbe [10]. The numerical results obtained in this paper 
contrast with some experimental results in the literature like the work of Flowers et al. [26], where an increase in the equivalence ratio resulted into a decrease in the ignition delay. Aichlmayr et al. also observed this contradiction in their work [27]. They explained this contradiction by performing adiabatic calculations. They state that the charges do not reach the same temperature following the adiabatic compression. Mixture specific heats increase with equivalence ratio. Consequently for equal compression ratios, a lean mixture will have a greater temperature following compression than a rich mixture, and therefore a shorter ignition time. The numerical results obtained in this paper should and will be completed by taking the heat losses into account. Heating by compression will probably be no longer an important factor when heat transfer correlations will be added to the modelling, hence obtaining results that are probably in the direction of what Flowers et al. obtained.

Figure 7 illustrates the influence of the compression ratio on the ignition delay at an equivalence ratio of 0.4 , using the mechanism of 29 reactions. By increasing the compression ratio, the ignition delay decreases. This was also observed by Aichlmayr et al. in a miniature free-piston HCCI engine [27] and also in a Diesel engine [28,29]. For a same equivalence ratio, a higher compression ratio causes a smaller end-volume in the cylinder before ignition, resulting in an overall higher concentration of all the species. This higher concentration causes the overall reaction rate to increase and thus the ignition delay to decrease. It is also shown that at a compression rate of 10 no ignition takes place at temperatures lower than $320 \mathrm{~K}$. This implies that, after the Top Dead Center, when the pressure decreases, ignition is not possible, due to the fact that the overall reaction rate is too low. Furthermore, at a compression ratio of 10 and 16 the ignition times (Figure 7), calculated using the Chalmers mechanism, correspond perfectly to the simulated ignition delays using the mechanism of 29 reactions at lower inlet temperatures. 


\section{Experimental validation on a CFR engine}

To validate the performed calculations, experiments are performed on a CFR engine, using iso-octane as fuel. The mono-cylinder engine has a cylinder capacity of $611 \mathrm{~cm}^{3}$, an engine speed of $600 \mathrm{rpm}$, a variable compression ratio (4 until 13.5), a variable inlet temperature of the mixture ( $303 \mathrm{~K}$ until $363 \mathrm{~K})$ and an inlet pressure of $1 \mathrm{bar}$.

For a compression ratio of 9 , for each studied equivalence ratio $(0.25$ until 0.60$)$, isooctane does not ignite at the inlet conditions (temperatures between $303 \mathrm{~K}$ and $363 \mathrm{~K}$, inlet pressure of 1 bar). At a compression ratio of 11.2, iso-octane ignites only temporarily for a short time at temperatures above $340 \mathrm{~K}$, which means that 11.2 can be considered to be the Critical Compression Ratio (CCR) needed for iso-octane to autoignite in these experimental conditions (equivalence ratio of 0.25 , the smallest value obtainable in this engine). In these experimental conditions, the calculations show a CCR of 10 at temperatures below $320 \mathrm{~K}$. This difference can be explained by the used mechanism, which does not take into account the heat losses to the wall and the inlet valve closing (10 CAD on this CFR engine). Curran et al. [30] find a CCR of 10.7 in a CFR engine at $500 \mathrm{rpm}$ with an intake pressure of 1.2 bar and an inlet temperature of $448 \mathrm{~K}$. In view of these experimental conditions which do not differ much from the conditions used in this work, the CCR found by Curran et al. corresponds well with the CCR found in this paper. For a compression ratio of 13.2, Figure 8 shows that the trends of the experiments and the calculations are similar. There is, however, a deviation of approximately $10 \mathrm{CAD}$, which could be explained as for the other compression ratios, discussed previously.

Since the experiments validate the mechanism, it can be considered realistic. Therefore, contour-maps of auto-ignition area for several inlet temperatures $(300 \mathrm{~K}<\mathrm{T}<400 \mathrm{~K})$, compression ratios (10-16) and equivalence ratios (0.2 and 0.7$)$ can be deduced from the 
modeling results Figure 9 and Figure 10. These contour-maps could be of great interest for optimization of engine parameters used in auto-ignition combustion (HCCI).

\section{Conclusion}

The semi-reduced ( 70 species, 210 reactions) and the skeletal (27 species, 29 reactions) chemical reaction mechanisms for iso-octane are constructed successfully from a detailed iso-octane mechanism ( 84 species, 412 reactions).

For low inlet temperatures $(\mathrm{T}<750 \mathrm{~K})$ the simulations of the ignition times are in very good agreement with those obtained with the detailed Chalmers iso-octane mechanism. The reduced mechanisms are also in good agreement with the complete Nancy isooctane mechanism, but at inlet temperatures lower than $600 \mathrm{~K}$.

For HCCI purposes the reduced mechanism of 29 reactions shows perfect coherence with both Chalmers and Nancy iso-octane combustion mechanisms and can be perfectly used for future aerodynamics applications in CFD codes.

Concerning the ignition delay it is shown that it decreased with

- an increasing temperature,

- a decreasing equivalence ratio

- an increasing compression ratio.

The temperature has the highest influence, whereas the equivalence ratio shows the smallest influence.

The calculations are in good agreement with the experiments performed on the CFR engine.

However, fuel composition can also play an important role in the ignition and its effects will be studied for several mixtures of iso-octane, n-heptane, toluene and/or alcohol.

The species formed during combustion inside a cylinder will also be studied in the future to identify intermediary species, responsible for the auto-ignition phenomenon. 


\section{References}

1 Huang Y., Sung C. J. and Eng J. A. Dilution limits of $n$-butane/air mixtures under conditions relevant to HCCI combustion. Combust. Flame 2004 ; 136 : 457-466.

2 Tanaka S., Ayala F. and Keck J.C. A Reduced Chemical Kinetic Model For HCCI Combustion Of Primary Reference Fuels In A Rapid Compression Machine. Combust. Flame $2003 ; 133: 467-481$.

3 Tanaka S., Ayala, F., Keck J. C. and Heywood J. B. Two-stage ignition in HCCI combustion and HCCI control by fuels and additives. Combust. Flame $2003 ; 132$ : 219 239.

4 Griffiths J. F., MacNamara J. P., Sheppard C. G. W., Turton D. A. and Whitaker B. J. The relationship of knock during controlled autoignition to temperature inhomogeneities and fuel reactivity. Fuel $2002 ; 81: 2219-2225$.

5 Griffiths J.F., MacNamara J.P., Sheppard C.G.W., Turton D.A. and Whitaker B.J. The relationship of knock during controlled autoignition to temperature inhomogeneities and fuel reactivity, Fuel $2002 ; 81: 2219-2225$.

6 Curran H.J., Gaffuri P., Pitz, W.J. and Westbrook C.K. A comprehensive modeling study of iso-octane oxidation. Combust. Flame $2002 ; 129: 253-280$.

7 Bikas G. and Peters N., Kinetic Modelling of n-Decane Combustion and Autoignition. Combust. Flame $2001 ; 126: 1456-1475$.

8 Warnatz J., Maas U. and Dibble R.W. Combustion : physical and chemical fundamentals, modeling and simulation, experiments, pollutant formation, $3^{\text {rd }}$ edition. Springer ; 2000.

9 Embouazza M., Gicquel O. and Darabiha N. Modelling autoignition of HCCI engine by reduced tabulated chemistry, MCS, 8-13 June 2003, Marrakech. 
10 Lewis B. and Von Elbe G., Combustion, Flames and Explosions of Gases, $3^{\text {rd }}$ edition, Academic Press ; 1987.

11 Blin-Simiand N., Rigny R., Viossat V., Circan S. and Sahetchian K. Auto-ignition of hydrocarbon/air mixtures in a CFR engine: experimental and modeling study. Combust Sci Technol $1993 ; 88: 329-348$.

12 Blin-Simiand N., Jorand F., Keller K., Fidderer M. and Sahetchian K. Brief communication: ketohydroperoxides and ignition delay in Internal Combustion Engines. Combust. Flame $1998 ; 112: 278-282$.

13 Moreac G. Etude expérimentale et modélisation des interactions chimiques entre gaz résiduels et gaz frais dans l'allumage spontané homogène des moteurs à essence, Thèse Université d'Orléans, 2003, mars.

14 Faravelli T., Gaffuri P., Ranzi E. and Griffiths J.F. Detailed thermokinetic modelling of alkane autoignition as a tool for the optimization of performance of internal combustion engines, Fuel $1998 ; 77: 147-155$.

15 Ogink R. and Golovitchev V., Generalized skeletal reaction mechanism for Aliphatic hydrocarbons (from methane to iso-octane) for CFD Engine Modeling. First Biennial Meeting of The Scandinavian-Nordic Section of the Combustion Institute, Göteborg, Sweden, $2001: 151-156$.

16 Soyhan H.S. and Mauss F., Chemical kinetic modeling of combustion in internal combustion engines using reduced chemistry. Combust. Sci. Technol $2002 ; 174$ : 73 91.

17 Aneja R., Bolton B., Hakim N. and Pavlova-Mackinnon Z., Attaining Tier 2 Emissions Through Diesel Engine and Aftertreatment Integration - strategy and experimental results. Eighth Diesel Engine Emissions Reduction Conference - Detroit ; 2002. 


18 Golovitchev V. semi-detailed mechanism of iso-octane,
www.tfd.chalmers.se/ valeri/MECH.html (accessed in January 2004).

19 Glaude P.A., Fournet R., Warth V., Battin-Leclerc F., Come G.M. and Scacchi G., Complete mechanism for the oxidation of iso-octane. 2002, http://www.ensic.inplnancy.fr/ENSIC/DCPR/Anglais/GCR/generatedmecanisms/isooctane (Accessed in march 2004).

20 Simon Y., Scacchi G. and Baronnet F. Etude des réactions d'oxydation du n-heptane et de l'isooctane. Can. J. Chem. 1996 ; 74 : 1391-1402.

21 Banerjee I. and Ierapetritou M. G. Development of an adaptive chemistry model considering micromixing effects. Chem. Eng. Sci. 2003; 58 : 4537-4555.

22 Dixon-Lewis G. Computer modeling of combustion reactions in flowing systems with transport : combustion chemistry. Springer-Verlag ; 1984.

$23 \mathrm{Lu}$ T., Ju Y. and Law C.K. Complex CSP for chemistry reduction and analysis. Combust. Flame $2001 ; 126: 1445-1455$.

24 Lovas T., Nilsson D. and Mauss F., Automatic reduction procedure for chemical mechanisms applied to premixed methane/air flames. Twenty-Eighth Symposium (International) on Combustion ; $2000: 1809-1815$.

25 MacNamara J. P. and Simmie J. M. The high temperature oxidation of pyrrole and pyridine ; ignition delay times measured behind reflected shock waves. Combust. Flame $2003 ; 133: 231-239$.

26 Flowers D., Aceves S., Smith R., Torre J., Girard J. and Dibble R. HCCI in a CFR engine: Experiments and detailed kinetic modeling, SAE 2000-01-0328.

27 Aichlmayr H. T., Kittelson D. B. and Zachariah M. R. Miniature free-piston homogeneous charge compression ignition engine-compressor concept-Part II: modeling HCCI combustion in small scales with detailed homogeneous gas phase chemical kinetics. Chem. Eng. Sci. 2002 ; 57 : 4173-4186. 
H. Machrafi et al.

28 Parlak A., Yasar H. and Sahin B. Performance and exhaust emission characteristics of a lower compression ratio LHR Diesel engine. Energy Convers. Manage 2003 ; 44 : 163-175.

29 Selim M. Y. E., Radwan M. S. and Elfeky S. M. S. Combustion of jojoba methyl ester in an indirect injection diesel engine . Renew. energy $2003 ; 28$ : 1401-1420.

30 Curran H.J., Pitz W.J., Westbrook C.K., Callahan C.V. and Dryer F.L. Oxidation of automotive primary reference fuels at elevated pressures. Twenty-seven Symposium (International) on Combustion ; 1998 : 379-387. 
Machrafi et al.

\begin{tabular}{|c|c|c|c|c|c|c|c|c|c|}
\hline \multirow[t]{2}{*}{ Norm } & \multicolumn{2}{|c|}{$\begin{array}{c}\mathrm{HC} \\
{[\mathrm{g} / \mathrm{km}]}\end{array}$} & \multicolumn{2}{|c|}{$\begin{array}{c}\mathrm{CO} \\
{[\mathrm{g} / \mathrm{km}]}\end{array}$} & \multicolumn{2}{|c|}{$\begin{array}{c}\mathrm{HC}+\mathrm{NO}_{\mathrm{x}} \\
{[\mathrm{g} / \mathrm{km}]}\end{array}$} & \multicolumn{2}{|c|}{$\begin{array}{c}\mathrm{NO}_{\mathrm{x}} \\
{[\mathrm{g} / \mathrm{km}]}\end{array}$} & \multirow{2}{*}{$\begin{array}{c}\text { Particulates } \\
{[\mathrm{g} / \mathrm{km}]} \\
\text { Diesel }\end{array}$} \\
\hline & Gasoline & Diesel & Gasoline & Diesel & Gasoline & Diesel & Gasoline & Diesel & \\
\hline $\begin{array}{l}\text { Euro II } \\
\text { (1992) }\end{array}$ & -- & -- & 2,20 & 1,00 & 0,50 & 0,90 & -- & -- & 0,10 \\
\hline $\begin{array}{l}\text { Euro III } \\
(2000)\end{array}$ & 0,20 & -- & 2,30 & 0,64 & -- & 0,56 & 0,15 & 0,50 & 0,05 \\
\hline $\begin{array}{l}\text { Euro IV } \\
(2005)\end{array}$ & 0,10 & -- & 1,00 & 0,50 & -- & 0,30 & 0,08 & 0,25 & 0,025 \\
\hline $\begin{array}{l}\text { Euro V } \\
\text { (2008 or } \\
2010 \text { ) }\end{array}$ & \multicolumn{9}{|c|}{ In establishment } \\
\hline
\end{tabular}

Table 1: Evolution of EURO standards for automotive emissions 
Machrafi et al.

\begin{tabular}{|c|c|c|c|c|}
\hline \multicolumn{2}{|c|}{ Reactions } & $\mathrm{A}[\mathrm{mole}-\mathrm{cm}-\mathrm{s}-\mathrm{K}]$ & $\mathrm{b}[-]$ & $\mathrm{E}[\mathrm{kJ} / \mathrm{mole}]$ \\
\hline 1 & $\mathrm{IC} 8 \mathrm{H} 18=\mathrm{IC} 3 \mathrm{H} 7 *+\mathrm{NEOC} 5 \mathrm{H} 11^{*}$ & $2.00 \mathrm{E}+16$ & 0.0 & 326.57 \\
\hline 2 & $\mathrm{IC} 8 \mathrm{H} 18+\mathrm{OH}^{*}=\mathrm{CC} 8 \mathrm{H} 17^{*}+\mathrm{H} 2 \mathrm{O}$ & $2.48 \mathrm{E}+13$ & 0.0 & 1.84 \\
\hline 3 & $\mathrm{IC} 8 \mathrm{H} 18+\mathrm{O} 2=\mathrm{AC} 8 \mathrm{H} 17^{*}+\mathrm{HO} 2^{*}$ & $3.72 \mathrm{E}+13$ & 0.0 & 205.15 \\
\hline 4 & $\mathrm{IC} 8 \mathrm{H} 18+\mathrm{O} 2=\mathrm{DC} 8 \mathrm{H} 17^{*}+\mathrm{HO} 2^{*}$ & $2.51 \mathrm{E}+13$ & 0.0 & 205.15 \\
\hline 5 & $\mathrm{IC} 8 \mathrm{H} 18+\mathrm{HO} 2^{*}=\mathrm{CC} 8 \mathrm{H} 17^{*}+\mathrm{H} 2 \mathrm{O} 2$ & $2.02 \mathrm{E}+12$ & 0.0 & 60.29 \\
\hline 6 & $\mathrm{DC} 8 \mathrm{H} 17^{*}+\mathrm{O} 2=\mathrm{C} 8 \mathrm{H} 17 \mathrm{OO}^{*}$ & $2.50 \mathrm{E}+19$ & -2.5 & 0.000 \\
7 & $\mathrm{C} 8 \mathrm{H} 17 \mathrm{OO} *=\mathrm{C} 8 \mathrm{H} 16 \mathrm{OOH}{ }^{*}$ & $3.38 \mathrm{E}+12$ & 0.0 & 119.32 \\
\hline 8 & $\mathrm{C} 8 \mathrm{H} 16 \mathrm{OOH} *+\mathrm{O} 2=\mathrm{C} 8 \mathrm{H} 16 \mathrm{OOHOO} *$ & $2.20 \mathrm{E}+19$ & -2.5 & 0.000 \\
\hline 9 & $\mathrm{C} 8 \mathrm{H} 16 \mathrm{OOHOO} * \mathrm{C} 8 \mathrm{H} 15 \mathrm{O} 4 \mathrm{H} 2 *$ & $4.00 \mathrm{E}+12$ & 0.0 & 119.32 \\
\hline 10 & $\mathrm{C} 8 \mathrm{H} 15 \mathrm{O} 4 \mathrm{H} 2 *=\mathrm{OH}^{*}+\mathrm{C} 7 \mathrm{H} 14 \mathrm{CHO}(\mathrm{OOH})$ & $2.00 \mathrm{E}+11$ & 0.0 & 31.40 \\
\hline 11 & $\mathrm{C} 7 \mathrm{H} 14 \mathrm{CHO}(\mathrm{OOH})=\mathrm{C}^{*} \mathrm{H} 13 \mathrm{CO} *+\mathrm{CH} 2 \mathrm{O}+\mathrm{OH} *$ & $2.05 \mathrm{E}+15$ & 0.0 & 173.33 \\
\hline 12 & $\mathrm{NEOC} 5 \mathrm{H} 11^{*}=\mathrm{C} 3 \mathrm{H} 6+\mathrm{C} 2 \mathrm{H} 5^{*}$ & $3.587 \mathrm{E}+16$ & -1.28 & 133.69 \\
\hline
\end{tabular}

Table 2 : Important reactions of iso-octane auto-ignition [18]

Note: $A, C$ and $D$ represents several isomers of $C 8 H 17^{*}$ radicals. 
Machrafi et al.

\begin{tabular}{|c|c|c|c|c|}
\hline & REACTIONS CONSIDERED & $\mathrm{A}$ & $\mathrm{b}$ & $\mathrm{E}[\mathrm{kJ} / \mathrm{mole}]$ \\
\hline 1. & $\mathrm{H} 2+\mathrm{O}=>\mathrm{H}+\mathrm{OH}$ & $1.82 \mathrm{E}+10$ & 1.0 & 37.26 \\
\hline \multirow[t]{2}{*}{2.} & $\mathrm{H} 2 \mathrm{O} 2+\mathrm{OH}=\mathrm{H} 2 \mathrm{O}+\mathrm{HO} 2$ & $1.00 \mathrm{E}+13$ & 0.0 & 7.54 \\
\hline & Reverse Arrhenius coefficients: & $2.03 E+13$ & 0.0 & 146.04 \\
\hline \multirow[t]{2}{*}{3.} & $\mathrm{H} 2 \mathrm{O}+\mathrm{M}=\mathrm{H}+\mathrm{OH}+\mathrm{M}$ & $2.19 \mathrm{E}+16$ & 0.0 & 439.61 \\
\hline & $\begin{array}{c}\text { H2O Enhanced by } 2.000 E+01 \\
\text { H2O Enhanced by } 2.100 E+01 \\
C O \text { Enhanced by } 2.000 E+00 \\
\text { H2 Enhanced by } 3.300 E+00\end{array}$ & & & \\
\hline 4. & $\mathrm{HO} 2+\mathrm{HO} 2=>\mathrm{H} 2 \mathrm{O} 2+\mathrm{O} 2$ & $5.78 \mathrm{E}+12$ & 0.0 & 23.74 \\
\hline \multirow[t]{2}{*}{5.} & $\mathrm{H} 2 \mathrm{O} 2(+\mathrm{M})=\mathrm{OH}+\mathrm{OH}(+\mathrm{M})$ & $3.00 \mathrm{E}+14$ & 0.0 & 203.06 \\
\hline & $\begin{array}{c}\text { Low pressure limit: } \\
\text { TROE centering coefficients: } 0.1 \quad 1.0 \quad 0.1 E+09 \\
\text { H2 Enhanced by } 2.000 E+00 \\
\text { H2O Enhanced by } 1.200 E+01 \\
\text { CO Enhanced by } 1.900 E+00 \\
\text { CO2 Enhanced by } 3.200 E+00\end{array}$ & $0.20000 E+18$ & 0.0 & 203.06 \\
\hline 6. & $\mathrm{CO}+\mathrm{HO} 2=>\mathrm{CO} 2+\mathrm{OH}$ & $1.51 \mathrm{E}+14$ & 0.0 & 99.02 \\
\hline 7. & $\mathrm{CO}+\mathrm{O}+\mathrm{M}=\mathrm{CO} 2+\mathrm{M}$ & $5.89 \mathrm{E}+15$ & 0.0 & 17.17 \\
\hline \multirow[t]{2}{*}{8.} & $\mathrm{CO} 2+\mathrm{O}=\mathrm{CO}+\mathrm{O} 2$ & $2.75 \mathrm{E}+12$ & 0.0 & 183.51 \\
\hline & Reverse Arrhenius coefficients: & $3.25 E+11$ & 0.0 & 153.53 \\
\hline 9. & $\mathrm{CH} 2 \mathrm{O}+\mathrm{O} 2+\mathrm{M}=>\mathrm{H}+\mathrm{CO}+\mathrm{M}+\mathrm{HO} 2$ & $6.20 \mathrm{E}+16$ & 0.0 & 154.91 \\
\hline 10. & $\mathrm{HCO}+\mathrm{O} 2=>\mathrm{CO}+\mathrm{HO} 2$ & $3.98 \mathrm{E}+12$ & 0.0 & 0.00 \\
\hline 11. & $\mathrm{CH} 2 \mathrm{O}+\mathrm{HO} 2=>\mathrm{HCO}+\mathrm{H} 2 \mathrm{O} 2$ & $2.17 \mathrm{E}+11$ & 0.0 & 33.49 \\
\hline 12. & $\mathrm{C} 2 \mathrm{H} 5+\mathrm{O} 2=>\mathrm{C} 2 \mathrm{H} 4+\mathrm{HO} 2$ & $1.00 \mathrm{E}+12$ & 0.0 & 20.93 \\
\hline 13. & $\mathrm{C} 2 \mathrm{H} 4+\mathrm{H}=>\mathrm{C} 2 \mathrm{H} 3+\mathrm{H} 2$ & $1.51 \mathrm{E}+07$ & 2.0 & 25.12 \\
\hline 14. & $\mathrm{IC} 3 \mathrm{H} 7+\mathrm{O} 2=>\mathrm{C} 3 \mathrm{H} 6+\mathrm{HO} 2$ & $1.00 \mathrm{E}+12$ & 0.0 & 20.93 \\
\hline 15. & $\mathrm{C} 3 \mathrm{H} 6+\mathrm{OH}=>\mathrm{C} 2 \mathrm{H} 5+\mathrm{CH} 2 \mathrm{O}$ & $1.00 \mathrm{E}+12$ & 0.0 & 0.00 \\
\hline 16. & $\mathrm{IC} 8 \mathrm{H} 18+\mathrm{OH}=>\mathrm{CC} 8 \mathrm{H} 17+\mathrm{H} 2 \mathrm{O}$ & $2.48 \mathrm{E}+13$ & 0.0 & 1.84 \\
\hline 17. & $\mathrm{IC} 8 \mathrm{H} 18+\mathrm{HO} 2=\mathrm{CC} 8 \mathrm{H} 17+\mathrm{H} 2 \mathrm{O} 2$ & $2.02 \mathrm{E}+12$ & 0.0 & 60.29 \\
\hline 18. & $\mathrm{CC} 8 \mathrm{H} 17=>\mathrm{IC} 4 \mathrm{H} 8+\mathrm{IC} 4 \mathrm{H} 9$ & $4.28 \mathrm{E}+12$ & 0.0 & 115.56 \\
\hline 19. & $\mathrm{IC} 6 \mathrm{H} 13=>\mathrm{IC} 3 \mathrm{H} 7+\mathrm{C} 3 \mathrm{H} 6$ & $2.51 \mathrm{E}+13$ & 0.0 & 118.07 \\
\hline 20. & $\mathrm{IC} 4 \mathrm{H} 9+\mathrm{O} 2=>\mathrm{IC} 4 \mathrm{H} 8+\mathrm{HO} 2$ & $1.00 \mathrm{E}+12$ & 0.0 & 20.93 \\
\hline 21. & $\mathrm{IC} 4 \mathrm{H} 8+\mathrm{OH}=>\mathrm{IC} 3 \mathrm{H} 7+\mathrm{CH} 2 \mathrm{O}$ & $1.51 \mathrm{E}+12$ & 0.0 & 0.00 \\
\hline 22. & $\mathrm{C} 2 \mathrm{H} 3+\mathrm{O} 2=>\mathrm{CH} 2 \mathrm{O}+\mathrm{HCO}$ & $3.98 \mathrm{E}+12$ & 0.0 & -1.05 \\
\hline 23. & $\mathrm{CC} 8 \mathrm{H} 17+\mathrm{HO} 2=>\mathrm{IC} 6 \mathrm{H} 13+\mathrm{C} 2 \mathrm{H} 3+\mathrm{H} 2 \mathrm{O} 2$ & $2.00 \mathrm{E}+12$ & 0.0 & 0.00 \\
\hline \multirow[t]{2}{*}{24.} & $\mathrm{CC} 8 \mathrm{H} 17+\mathrm{O} 2=\mathrm{R} 2 \mathrm{C} 8 \mathrm{H} 17 \mathrm{OO}$ & $2.50 \mathrm{E}+19$ & -2.5 & 0.00 \\
\hline & Reverse Arrhenius coefficients: & $1.79 E+13$ & 0.0 & 103.92 \\
\hline 25. & $\mathrm{IC} 8 \mathrm{H} 18+\mathrm{O} 2+\mathrm{O} 2=>\mathrm{R} 2 \mathrm{C} 8 \mathrm{H} 17 \mathrm{OO}+\mathrm{HO} 2$ & $2.10 \mathrm{E}+17$ & 0.0 & 205.15 \\
\hline \multirow[t]{2}{*}{26.} & $\mathrm{R} 2 \mathrm{C} 8 \mathrm{H} 17 \mathrm{OO}=\mathrm{C} 8 \mathrm{H} 16 \mathrm{OOH}$ & $3.28 \mathrm{E}+12$ & 0.0 & 119.32 \\
\hline & Reverse Arrhenius coefficients: & $1.80 E+11$ & 0.0 & 84.15 \\
\hline \multirow[t]{2}{*}{27.} & $\mathrm{C} 8 \mathrm{H} 16 \mathrm{OOH}+\mathrm{O} 2=\mathrm{R} 2 \mathrm{C} 8 \mathrm{H} 16 \mathrm{OOHOO}$ & $2.12 \mathrm{E}+19$ & -2.5 & 0.00 \\
\hline & Reverse Arrhenius coefficients: & $7.00 E+12$ & 0.0 & 91.19 \\
\hline 28. & $\mathrm{R} 2 \mathrm{C} 8 \mathrm{H} 16 \mathrm{OOHOO}=>\mathrm{OH}+\mathrm{C} 7 \mathrm{H} 14 \mathrm{CHO}(\mathrm{OOH})$ & $4.80 \mathrm{E}+12$ & 0.0 & 119.32 \\
\hline 29. & $\mathrm{C} 7 \mathrm{H} 14 \mathrm{CHO}(\mathrm{OOH})=>\mathrm{CO}+\mathrm{IC} 6 \mathrm{H} 13+\mathrm{CH} 2 \mathrm{O}+\mathrm{OH}$ & $2.05 \mathrm{E}+15$ & 0.0 & 173.33 \\
\hline
\end{tabular}

Table 3: The reduced mechanism of iso-octane with 29 reactions and 27 species from Chalmers scheme 
Machrafi et al.

\begin{tabular}{|c|c|}
\hline Engine parameter & Value \\
\hline Engine speed & $600 \mathrm{rpm}$ \\
\hline Ratio connecting rod length to crank-arm radius & 3.26 \\
\hline Displacement volume & $611 \mathrm{~cm}^{3}$ \\
\hline
\end{tabular}

Table 4 : Engine parameters 
Machrafi et al.

\section{Captions to illustrations:}

Figure 1 : NOx and particulate reduction at low temperatures with the HCCI method [17]

Figure 2 : Cool flame of HCCI combustion [14]

Figure 3 : Ignition delay times in stoichiometric n-heptane/air mixtures; negative temperature coefficients occur just below $1000 \mathrm{~K}$ [8]

Figure 4 : Ignition delays as a function of inlet temperature at equivalence ratio of 0.6 and compression ratio of 14 .

Figure 5 : Ignition delay as function of inlet temperature and equivalence ratio using 29 reactions mechanism (unless otherwise specified) at a compression ratio of 16 . Comparison between skeletal mechanism and Chalmers mechanism at an equivalence ratio of 0.2 and 0.7 . Engine speed is $600 \mathrm{rpm}$.

Figure 6 : Normalized concentrations of iso-octane and peroxides, cylinder pressure an heat exchange as function of time at $\mathrm{T}_{\text {inlet }}=363 \mathrm{~K}$ and an equivalence ratio of 0.2 (up) and 0.7 (down). Engine speed is $600 \mathrm{rpm}$. Results obtained with the skeletal mechanism.

Figure 7 : Ignition delay as a function of the compression ratio and the inlet temperature using a reduced mechanism of 29 reactions at an equivalence ratio of 0.4 Engine speed is $600 \mathrm{rpm}$.

Figure 8 : Validation of performed calculations by means of CFR experiments. Equivalence ratio $=0.262$. Compression ratio $=13.2$. Engine speed $=600 \mathrm{rpm}$.

Figure 9 : Ignition delay in $\mathrm{CAD}$ as a function of inlet temperature and compression ratio at an equivalence ratio of 0.2 .

Figure 10 : Ignition delay in $\mathrm{CAD}$ as a function of inlet temperature and compression ratio at an equivalence ratio of 0.7 . 
Machrafi et al.

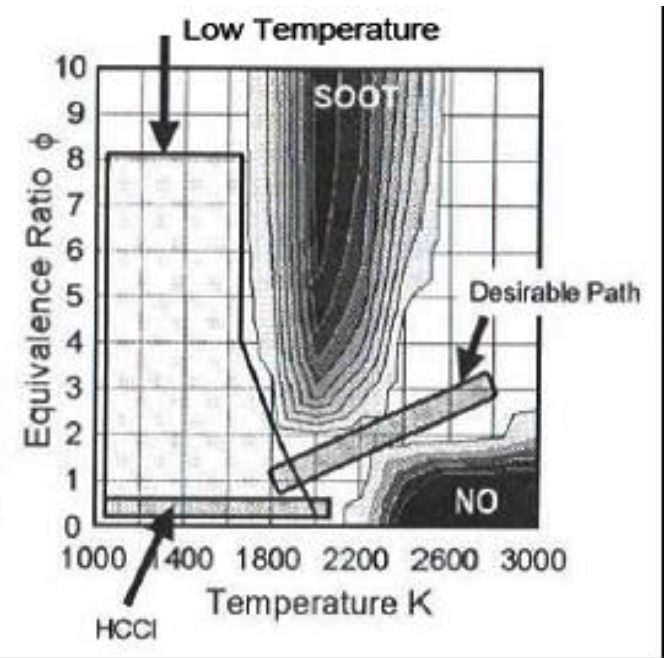

Figure 1: NOx and particulate reduction at low temperatures with the HCCI method [17] 
Machrafi et al.

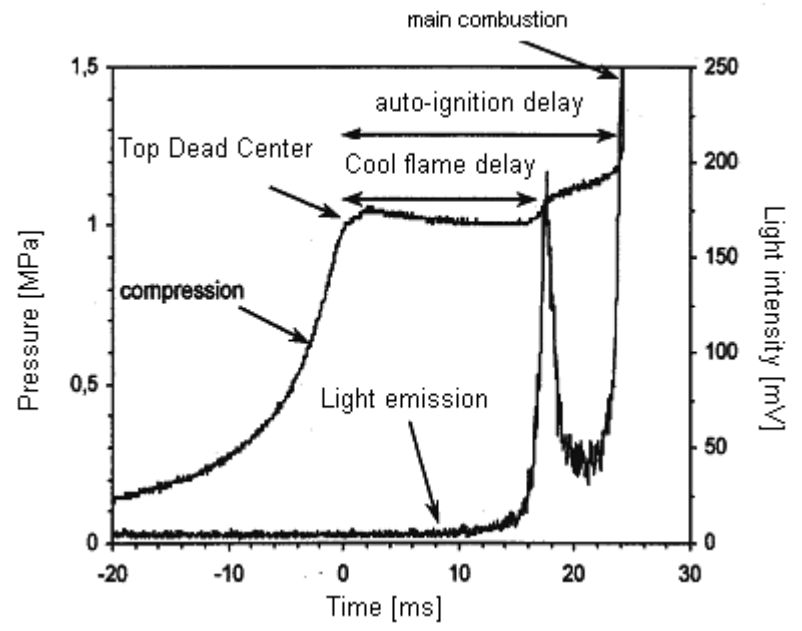

Figure 2 : Cool flame of HCCI combustion [14] 
Machrafi et al.

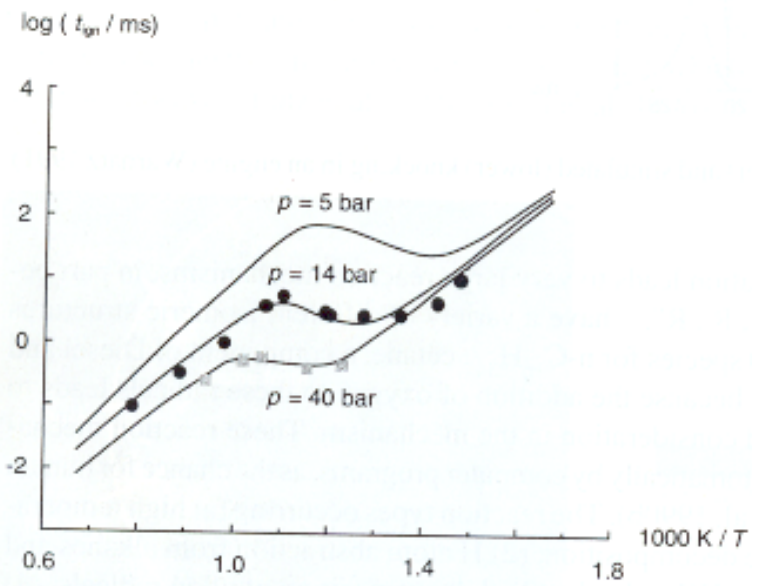

Figure 3: Ignition delay times in stoichiometric n-heptane/air mixtures; negative temperature coefficients occur just below $1000 \mathrm{~K}$ [8] 
Machrafi et al.

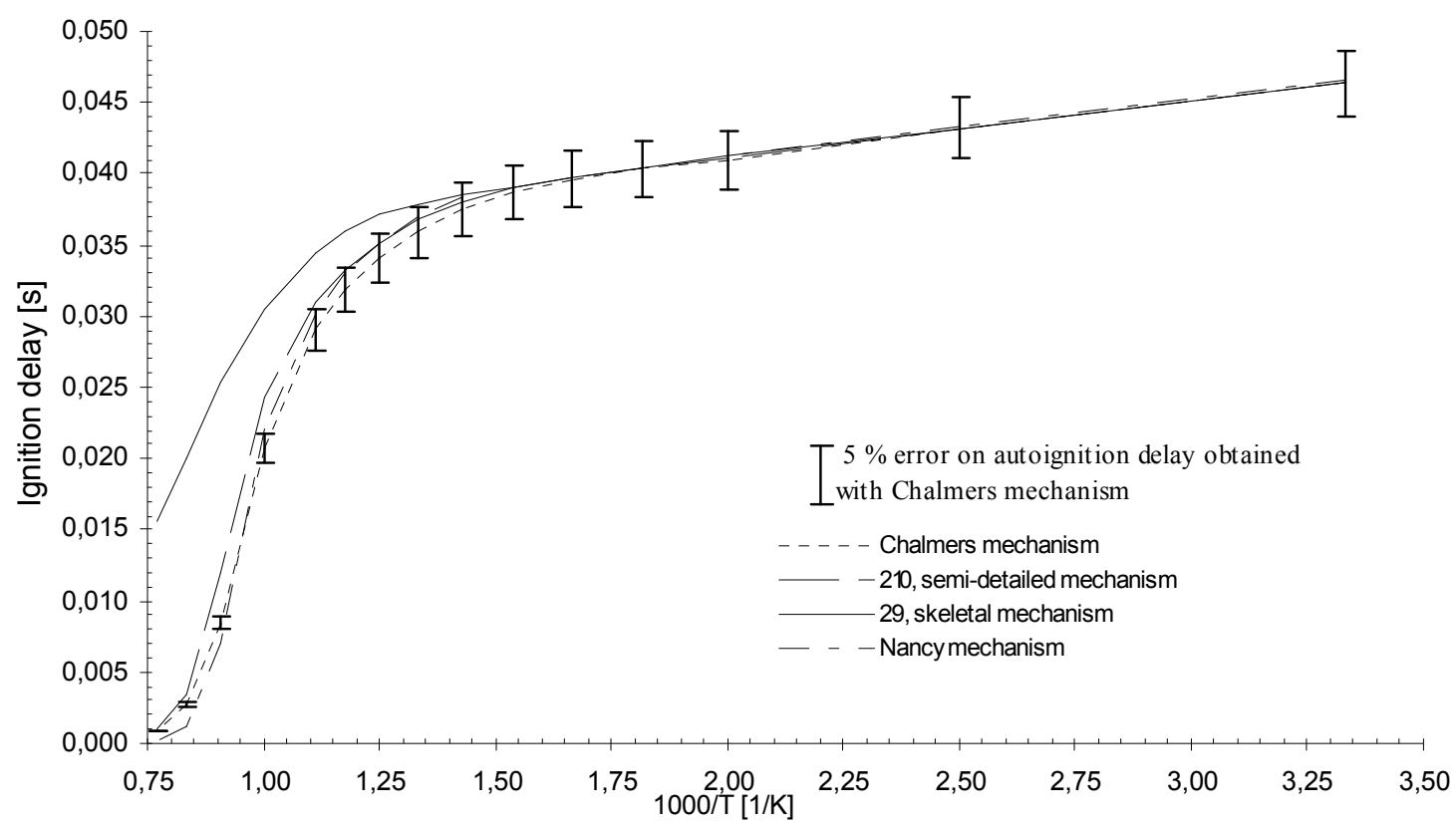

Figure 4 : Ignition delays as a function of inlet temperature at equivalence ratio of 0.6 and compression ratio of 14 . 


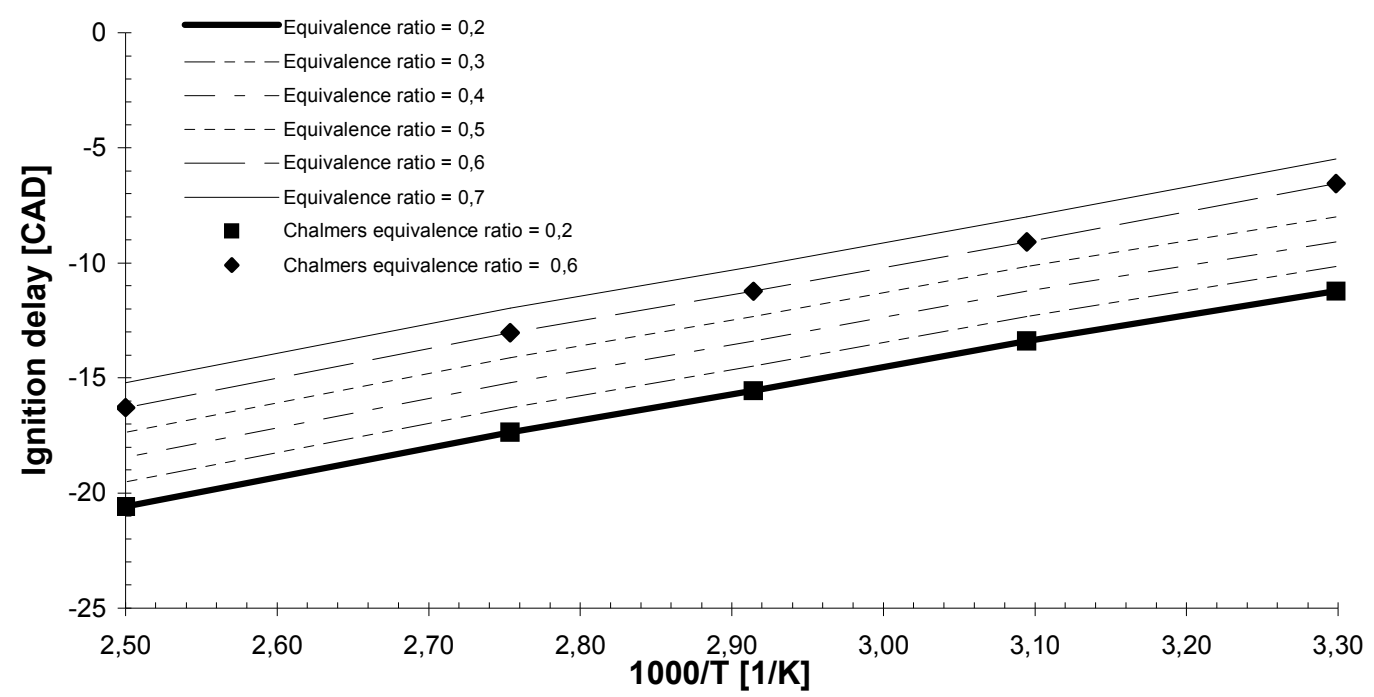

Figure 5 : Ignition delay as function of inlet temperature and equivalence ratio using 29 reactions mechanism (unless otherwise specified) at a compression ratio of 16. Comparison between skeletal mechanism and Chalmers mechanism at an equivalence ratio of 0.2 and 0.7 . Engine speed is $600 \mathrm{rpm}$. 
Machrafi et al.
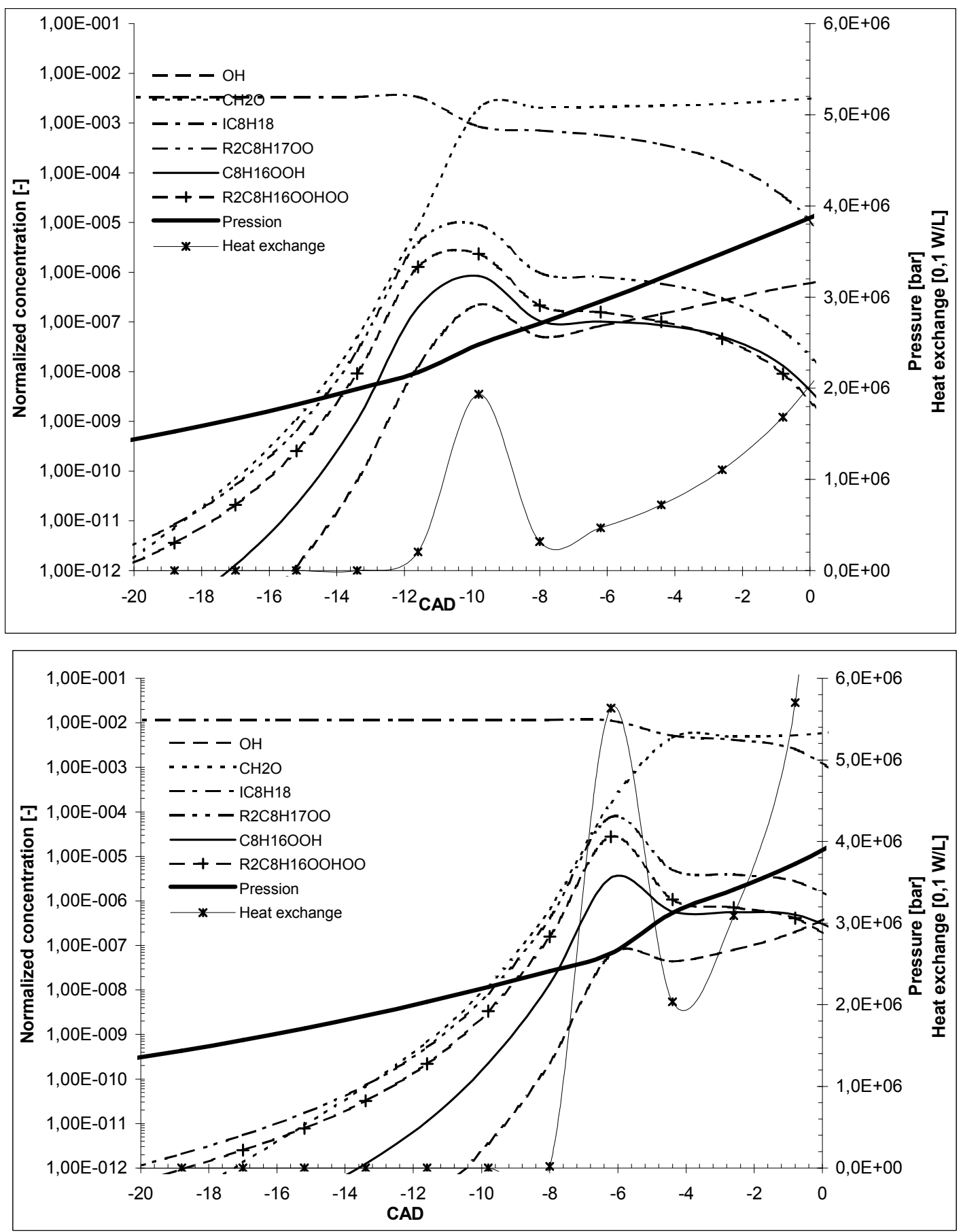

Figure 6 : Normalized concentrations of iso-octane and peroxides, cylinder pressure an heat exchange as function of time at $T_{\text {inlet }}=363 \mathrm{~K}$ and an equivalence ratio of 0.2 (up) and 0.7 (down). Engine speed is $600 \mathrm{rpm}$. Results obtained with the skeletal mechanism. 
Machrafi et al.

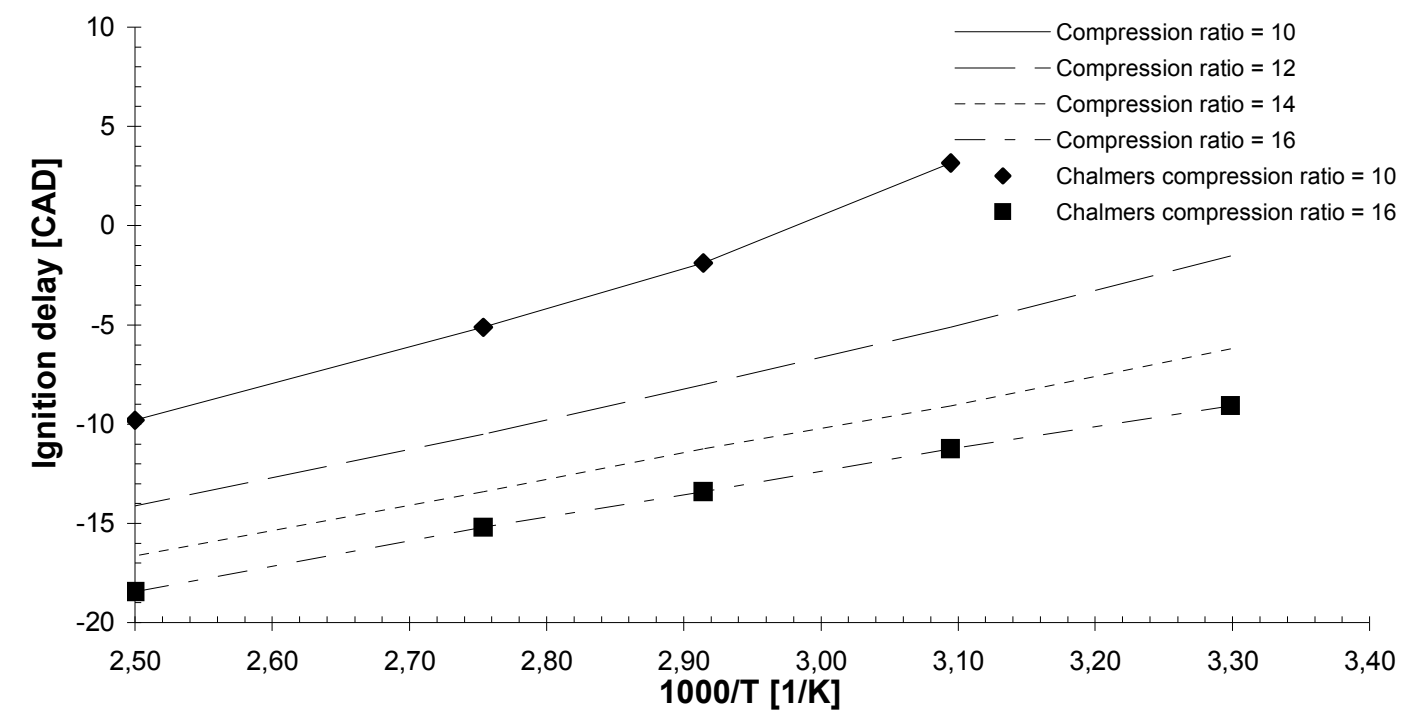

Figure 7 : Ignition delay as a function of the compression ratio and the inlet temperature using a reduced mechanism of 29 reactions at an equivalence ratio of 0.4 Engine speed is $600 \mathrm{rpm}$. 
Machrafi et al.

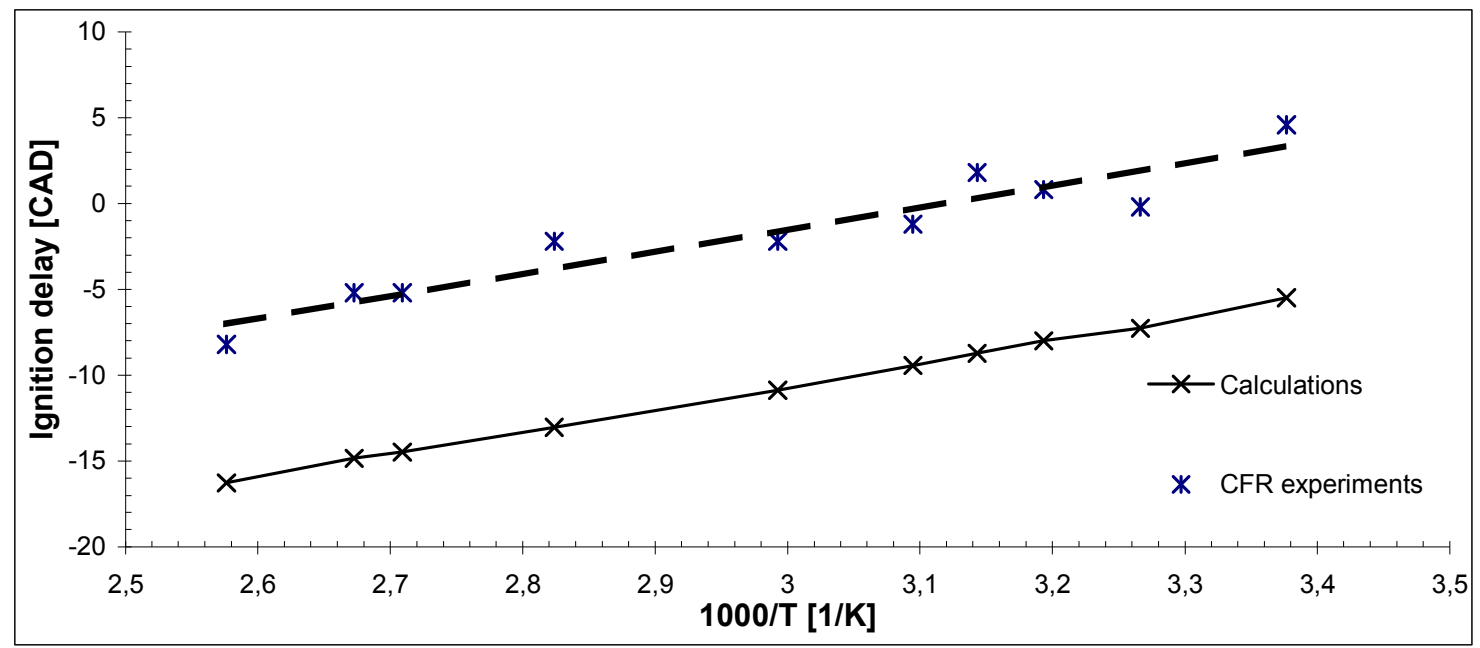

Figure 8 : Validation of performed calculations by means of CFR experiments.

Equivalence ratio $=0.262$. Compression ratio $=13.2$. Engine speed $=600 \mathrm{rpm}$. 
Machrafi et al.

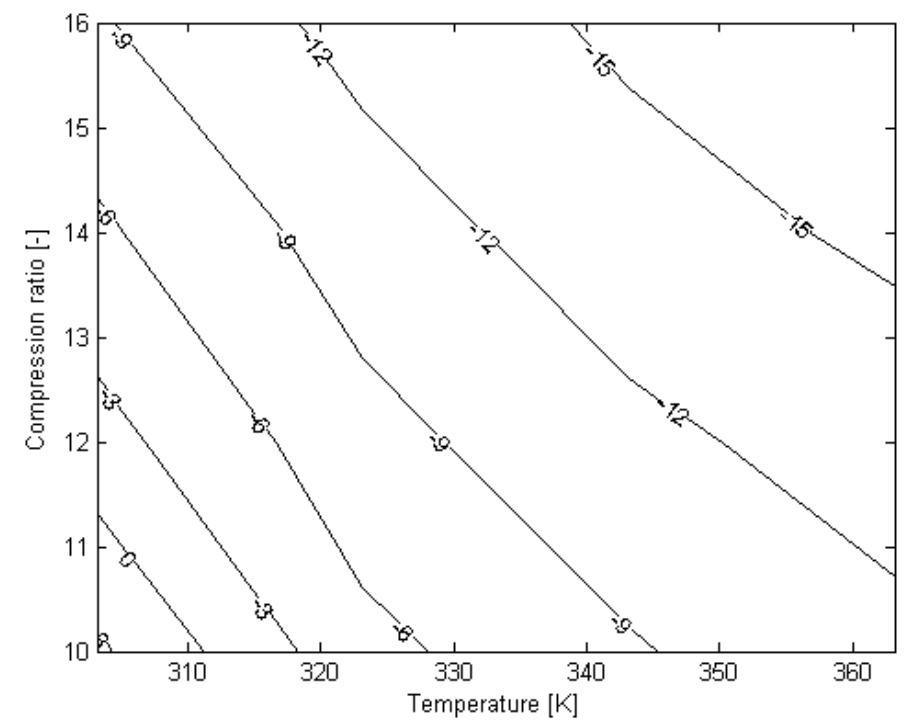

Figure 9: Ignition delay in CAD as a function of inlet temperature and compression ratio at an equivalence ratio of 0.2 . 
Machrafi et al.

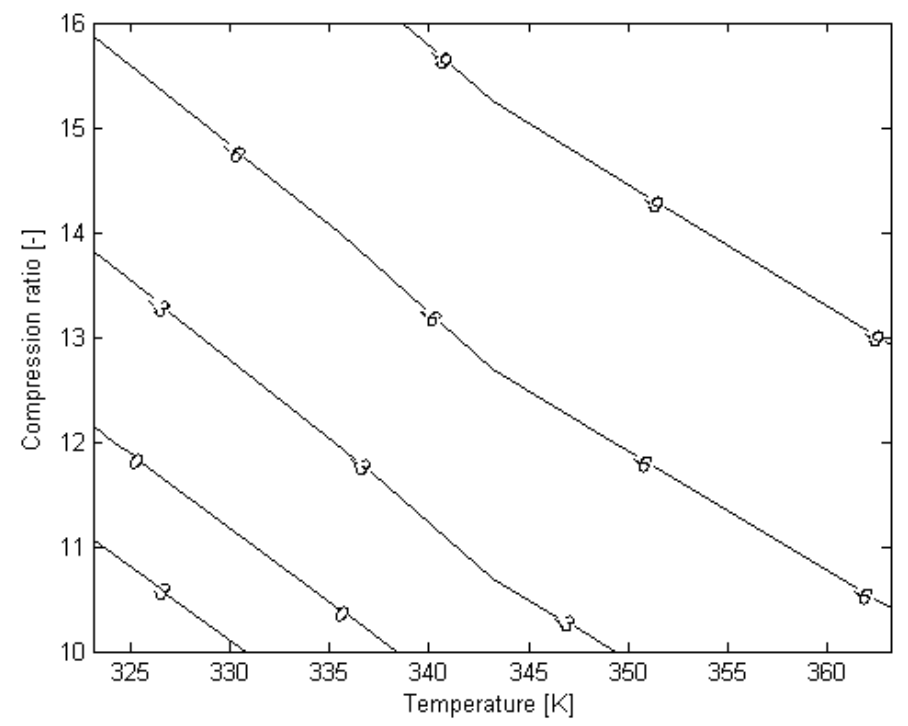

Figure 10: Ignition delay in CAD as a function of inlet temperature and compression ratio at an equivalence ratio of 0.7 . 